\title{
Getting kids active by participating in sport and doing It more often: focusing on what matters
}

\author{
Sandra Mandic ${ }^{1 *}$, Enrique García Bengoechea ${ }^{2}$ Emily Stevens ${ }^{1}$, Sophia Leon de la Barra ${ }^{3}$ and Paula Skidmore ${ }^{4}$
}

\begin{abstract}
Background: Reduced time dedicated to physical education and free play in recent decades emphasizes the need to promote opportunities for sport participation in adolescents in order to increase physical activity levels. The purpose of this study was to examine the association of sociodemographic and biological characteristics, behavioural patterns, and school-related and sport-specific variables with time spent participating in sport.

Methods: A total of 1837 secondary school students (age: 14.6 \pm 1.2 years; $50.9 \%$ boys) from 19 of 23 schools in the Otago Region (New Zealand) completed an online sport survey and Youth Physical Activity Questionnaire in 2009. Using multilevel modeling, we examined the association of individual-, school- and sport-related variables on sport participation and the amount of time spent in sports.
\end{abstract}

Results: Higher rates of sport participation were associated with lower neighbourhood deprivation scores (OR (95\% Cl): 0.75 (0.49-1.14), $0.57(0.38-0.86), 0.48(0.28-0.81))$, higher quintiles of physical activity (2.89 (2.10-3.96), 2.81 (1.684.70), 3.54 (2.24-5.57), 3.97 (1.99-7.95)), highest quintiles of screen time (1.58 (0.94-2.65), 1.99 (1.42-2.80), 2.17 (1.43$3.30), 1.88(1.37-2.57))$ and boys only school status (2.21 (1.57-3.10)). Greater amount of time spent in sports was associated with male gender (0.56 (0.43-0.74), lower neighbourhood deprivation scores (0.72 (0.59-0.93), 0.78 (0.581.04), 0.62 (0.39-1.00)), higher quintiles of physical activity (3.18 (2.29-4.41), 4.25 (2.91-6.20), 8.33 (5.58-12.44), 6.58 (4.07-10.64)), highest quintile of screen time (1.83 (1.31-2.56), greater availability of sports outside school (1.68 (1.222.32)), better sport management (2.57 (1.63-4.07)) and provision of sport courts at school (0.57 (0.40-0.81)). Conversely, obesity was associated with less time spent participating in sport $(0.50$ (0.31-0.80)).

Conclusion: Results support the use of sport participation as an effective strategy to increase physical activity levels and identify target groups and areas for interventions, program design and policy development. Interventions should focus on improving accessibility to sport programs for all adolescents, providing adequate sport grounds at school, and promoting good sport management practices. Programs and policies encouraging sport participation should address in particular the needs of adolescents living in deprived neighborhoods, those attending coeducational and girls-only schools, and those who are obese.

Keywords: Adolescents, Sports, Physical activity, Sport management, Schools, Social determinants

\section{Background}

Lack of physical activity (PA) and sedentary lifestyle in school-age children is a global health problem in both developed [1] and developing countries. [2] PA during childhood and adolescence has multiple health benefits. Therefore, opportunities to engage youth in PA such as sports, physical education classes, active transport and unstructured physical activities, are critical in encouraging

\footnotetext{
* Correspondence: sandra.mandic@otago.ac.nz

'School of Physical Education, University of Otago, PO Box 56, Dunedin, New Zealand

Full list of author information is available at the end of the article
}

healthy lifestyles in adolescents. With less time dedicated to physical education and free play in the recent decade, there is a greater need to promote opportunities for structured and unstructured PA for youth. [3] In addition, sports also provide important opportunities for students to contribute to the school community, which may cultivate an increased commitment to the school and school values [4].

Recent New Zealand data showed that $60 \%$ of boys and $50 \%$ of girls participate in sports outside of school time. [5] Participation in sports is associated with higher levels of PA in adolescents[6], contributes to $60 \%$ of

\section{Biomed Central}


daily moderate-to-vigorous PA in youth [7] and is one of the best predictors of PA in early adulthood. [8] Since approximately half of the youth sport practice time is spent in either sedentary or light-intensity activities [6,9], the actual percentage of youth meeting PA guidelines through sport participation most likely is overestimated.

Previous studies have examined factors associated with sport participation in adolescence using individual and school level variables including gender, socioeconomic status, weight status, self-efficacy for PA, enjoyment of PA and physical education, and school climate for PA. [10-12] Extending previous research, our study investigates relevant sociodemographic and biological characteristics of students, behavioural patterns, and school-related variables as potential correlates of sport participation and time spent participating in sport. In addition, we designed a survey and incorporated sport specific variables that have not been addressed in the past to examine their potential contribution to time spent participating in sport (such as availability of sports, suitability of competitions and coaches, quality of sport management and schools provisions and resources for sports). Study variables were chosen based on the physical activity and sport literature and on their relevance to practitioners, as determined in consultation with the Otago Secondary School Sports Association. Previous research found that school-age students were more likely to engage in PA when schools provided adequate space, sport grounds and adult supervision. [13] These factors may impact significantly students experience in sport, their motivation and opportunities for participation.

The purpose of this study was two-fold: 1) to examine individual- and school-related factors that are associated with sport participation in secondary school students; and 2) to examine individual-, school- and sport-related factors that influence amount of time spent in sports among sport participants. Exploring relevant factors associated with adolescents' participation in sport is important to take into account, since the greatest public health benefit is likely to occur from encouraging sedentary individuals to engage in physical activity. [14]. In addition, to maximize public health benefit along with other potential developmental and educational benefits derived from sport participation, it becomes critical to understand the influential factors, including sport-specific factors, associated with the amount of time spent in sport.

\section{Methods}

\section{Study design}

The Otago School Students Lifestyle Survey was conducted in 19 out of 23 secondary schools in the province of Otago, New Zealand, between October and December 2009. Cluster sampling was undertaken using schools as sample units. Purposive sampling was used with random classes from each school year invited to take part. A total of 2408 students from Years 9 to 13 were invited to take part in the web-based questionnaire. Students were given study information packages with separate information sheets and consent forms for student and parents. Students were required to sign a consent form to participate, while parents were only required to provide opt-out consent if they did not wish their child to participate.

The anonymous questionnaire was delivered and completed during classroom time. The questionnaire package included questions on demographics, PA, sedentary behaviour, sport participation, dietary habits, transportation habits and youth space preferences. Questionnaire items and data collection methods were pre-tested for comprehension and appropriateness by students from the target age group, school staff and experienced researchers. The online questionnaire was also pilottested to ensure that it could be completed within one class period and revisions were made to the questionnaire before data collection. The study was approved by the University of Otago Ethics Committee.

\section{Correlates and outcome measures}

\section{Student characteristics and school variables}

Basic demographic data collected included self-reported age, gender, and ethnicity. Neighbourhood socioeconomic status was assessed using the New Zealand Deprivation Index Score, which is derived from residential address and provides a measure of area level deprivation. [15] The deprivation index is an ordinal scale ranging from 1 (least deprived) to 10 (most deprived) and was used as a surrogate for students' socioeconomic status. For the purpose of the analysis, four categories were created: lowest (1-2), middle-low (3-5), middle-high (6-8) and highest (9-10) deprivation score. Weight status was based on body mass index which was calculated from self-reported heights and weights. Participants were categorized as normal, overweight or obese using the cut-off points for body mass index based on international data [16].

Place of residence was determined based on school location in Dunedin city area (urban schools, $\mathrm{n}=10$ ) or greater Otago area (rural schools, $n=9$ ). Educational status of the school included 3 categories: co-educational $(n=13)$, boys only $(n=3)$ and girls only schools $(n=3)$. Socioeconomic status of the school was based on school decile ranging from 1 (most deprived) to 10 (least deprived). School decile is determined by the proportion of students at the school with low socioeconomic status as defined by the student's home address. Decile 1 contains the $10 \%$ of schools with the highest proportion of students from low socioeconomic communities, while Decile 10 contains the lowest proportion of those students. 


\section{Sport questionnaire}

The sport questionnaire was developed in collaboration with Otago Secondary School Sports Association. The question "Are you involved in any sport or do you belong to any sport team?" was taken directly from New Zealand Youth '07 Survey. [5] Students were asked the question "How many hours per week do you spend in sport in school or sport out of school?" with the following response options: " $<1$ hour per week"; "1-2 hours per week"; "3-5 hours per week", or " $\geq 6$ hours per week". Due to a small number of participants, we combined categories " $<1$ hour per week" and "1-2 hours per week" into "Up to 2 hours per week".

Sport participants were asked to select up to 5 sports they participate in. For each sport, students were asked about availability, competitions, coaching, and management. A school sport resources score was created as a sum of individual responses to items related to school provisions and resources for sport ranging from 0 (low support) to 8 (high support). Students who did not participate in sports were asked about barriers that prevent them from participating in sports and were asked for suggestions for improving school sports. Students' responses were analysed inductively searching for emerging patterns. The questions related to sport availability, competition, coaching and school provisions for sports were newly developed and pretested in a pilot study on 30 students in 1 school undertaken in September 2009.

\section{Physical activity and screen time}

Self-reported PA (sports and other activities outside school, physical education classes, active transport) and screen time (playing computer games, using computer/internet, watching TV) in the previous week were assessed using a validated Youth Physical Activity Questionnaire for children. [17] Metabolic equivalents (METs) for each activity were determined from the compendium of PA for youth. [18] Thresholds values of 4 METs for moderate and 7 METs for vigorous PA were used [19]. PA data were truncated to 120 minutes per session to be consistent with objectively measured PA in adolescents. [20,21] Current threshold values of at least 60 minutes of moderate-tovigorous PA per day and up to 2 hours of screen time per day were used to identify students meeting guidelines for each behaviour. [22] In addition, quintiles of PA and screen time were created for further analysis.

\section{Data analysis}

We calculated descriptive statistics for all student demographics and school-level variables. To identify correlates of sport participation versus no participation, we conducted a multilevel logistic regression, using school as a cluster variable. This accounts for potential random effects in the dependent variable associated with clustering of the students within the schools. In this analysis, we examined univariate correlates of sport participation both at individual (age, gender, ethnicity, students' socioeconomic status, weight status, PA and screen time) and the school level (school decile, school setting (urban versus rural) and school educational status). Significant univariate correlates were entered into a multivariate model.

Among sport participants, we examined factors associated with greater time spent participating in sport using a multilevel ordinal logistic regression, with school as a cluster variable. The Brant test indicated that the proportional odds assumption was not violated; therefore, it is appropriate and valid to use ordinal logistic regression for this model. In addition to individual and school level correlates examined in the logistic regression model, we also included variables related to sport management and school support for sports. These questions were only answered by sport participants. We followed the same approach by first examining correlates at the univariate level, and then entering significant univariate correlates into a multivariate model. Data were analysed using Stata Version IC11 (Stata Corp., College Station, TX, USA).

\section{Results}

\section{Final study sample and descriptive statistics}

Twelve students refused to participate and 311 were absent from the class. A total of 2085 students took part in this questionnaire. We excluded from data analysis 94 participants with invalid questionnaires, 94 participants with incomplete sport questionnaire data and 60 participants who did not provide details on sport participation. Therefore, a total of 1837 students were included in this analysis. Mean age of participants was $14.6 \pm 1.2$ years with a similar percentage of boys and girls (Table 1). Most participants reported New Zealand European origin, were of normal weight, lived in less deprived neighbourhoods, and lived in an urban area. Half of the participants attended co-educational schools. Among all schools in the Otago region, school decile indicated moderate to low deprivation (school decile ranging from 4 to 10 ).

A total of 1291 students (70\%) participated in organized sports. The number of boys who participated was slightly higher than the number of girls $(72.3 \%$ vs. $68.2 \%$, $\mathrm{p}=0.054$ ). Sports participation was highest among adolescents from the least deprived neighbourhoods (77.5\%) compared to students from the most deprived neighbourhoods (62.5\%). The majority of sports were available at school and outside of school (Table 2). Most students perceived that sport competitions were suitable, coaches were available and suitable for the level of competition, and teams/sports were well managed. The majority of students playing sports perceived that their schools had sufficient sports grounds and the right sports gear, 
Table 1 Student characteristics and school variables

\begin{tabular}{|c|c|}
\hline & Total \\
\hline & $n=1837$ \\
\hline Age (years) (mean $\pm S D$ ) & $14.6 \pm 1.2$ \\
\hline \multicolumn{2}{|l|}{ Gender [n(\%)] } \\
\hline Boys & $935(50.9)$ \\
\hline Girls & $902(49.1)$ \\
\hline \multicolumn{2}{|l|}{ Ethnicity [n(\%)] } \\
\hline NZ European & $1435(78.1)$ \\
\hline Maori & $193(10.5)$ \\
\hline Other & 209 (11.4) \\
\hline \multicolumn{2}{|l|}{ NZ Deprivation score [n(\%)] } \\
\hline Low & $489(26.6)$ \\
\hline Middle-low & $691(37.6)$ \\
\hline Middle-high & $479(26.1)$ \\
\hline High & $112(6.1)$ \\
\hline \multicolumn{2}{|l|}{ BMI z-scores [n(\%)] } \\
\hline Under/normal weight & $1230(67.0)$ \\
\hline Overweight & $279(15.2)$ \\
\hline Obese & $107(5.8)$ \\
\hline \multicolumn{2}{|l|}{ Place of residence [n(\%)] } \\
\hline Urban & $1305(71.0)$ \\
\hline Rural & $532(29.0)$ \\
\hline \multicolumn{2}{|l|}{ Co-ed school status [n(\%)] } \\
\hline Co-ed & $976(53.1)$ \\
\hline Boys only & $450(24.5)$ \\
\hline Girls only & $411(22.4)$ \\
\hline School decile* (mean \pm SD) & $7.38 \pm 1.87$ \\
\hline
\end{tabular}

*Range 1-10; higher score represents lower deprivation.

provided good organisation of sport at the school, acknowledged sport results and offered adequate opportunities for both best and social players (Table 2). Students also felt they had sufficient input regarding the organisation of sport in their school. The composite score for school sport and resources reflected positive perceptions of school support for sports. Among all study participants, only $33 \%$ of students reported spending $\geq 6$ hours per week participating in sports. More time spent participating in sports was associated with an increased percentage of students meeting minimal PA guidelines (considering all types of PA) (no sport: 28.8\%; up to 2 hours: $29.3 \%$; 3 to 5 hours: $47.6 \%$; 6 or more hours: $74.9 \%$; $<0.001)$. Gender-specific data are presented in Figure 1.

\section{Correlates of sport participation}

In univariate logistic regression analyses, significant correlates of sport participation were gender, age, student's socioeconomic status, weight status, PA, screen time,
Table 2 Sport questionnaire items with descriptive statistics

\begin{tabular}{|c|c|}
\hline Sport participants & $\frac{\text { Yes response }}{(n=1283)}$ \\
\hline \multicolumn{2}{|l|}{ Availability* (mean \pm SD) } \\
\hline Is your sport available at school? (\%) & $79.3 \pm 31.9$ \\
\hline $\begin{array}{l}\text { Is your sport available outside of } \\
\text { school? (\%) }\end{array}$ & $85.4 \pm 28.2$ \\
\hline \multicolumn{2}{|l|}{ Sport management* (mean $\pm S D)$} \\
\hline $\begin{array}{l}\text { Are the [sport] competitions/games/ } \\
\text { events you compete in suitable for } \\
\text { your level of } \\
\text { performance? (\%) }\end{array}$ & $93.8 \pm 17.4$ \\
\hline Do you or your team have a coach? (\%) & $77.8 \pm 30.8$ \\
\hline $\begin{array}{l}\text { Is your coach suitable for } \\
\text { the level of competition? (\%) }\end{array}$ & $94.9 \pm 18.5$ \\
\hline Is your sport/team well managed? (\%) & $83.4 \pm 28.8$ \\
\hline \multicolumn{2}{|l|}{ School sport provisions and resources $[n(\%)]$} \\
\hline $\begin{array}{l}\text { My school has enough sport grounds } \\
\text { and courts }\end{array}$ & $1098(85.1)$ \\
\hline My school provides the right sport gear & $1126(87.2)$ \\
\hline Sport is well organized at my school & $1093(84.7)$ \\
\hline $\begin{array}{l}\text { Everyone can participate in sports } \\
\text { in my school }\end{array}$ & $1184(91.7)$ \\
\hline $\begin{array}{l}\text { My school offers good opportunities } \\
\text { for best players }\end{array}$ & $1157(89.6)$ \\
\hline $\begin{array}{l}\text { My school offers good opportunities } \\
\text { for social players }\end{array}$ & $1083(83.9)$ \\
\hline $\begin{array}{l}\text { Students can influence sport } \\
\text { organization }\end{array}$ & $1117(86.5)$ \\
\hline $\begin{array}{l}\text { Sport results and successes are } \\
\text { acknowledged in my school }\end{array}$ & $1203(93.2)$ \\
\hline School support resource score (range: 0-8) & $7.3 \pm 1.22$ \\
\hline
\end{tabular}

Students who do not participate in sports $(n=546)$

\begin{tabular}{llc}
\hline Barriers [n(\%)] & At school & $\begin{array}{c}\text { Outside } \\
\text { school }\end{array}$ \\
\hline It costs too much & $93(17.0)$ & $96(17.6)$ \\
I'm not good enough at sports & $180(33.0)$ & $167(30.6)$ \\
I'm not interested & $281(51.5)$ & $247(42.2)$ \\
It takes too much time & $167(30.6)$ & $157(28.8)$ \\
None of my friends are in sports & $127(23.3)$ & $114(20.9)$ \\
The sports I'm interested in & $147(26.9)$ & $77(14.1)$ \\
aren't available & & \\
Can't get there & $94(17.2)$ & $107(19.6)$ \\
I would feel shy, nervous or embarrassed & $133(24.4)$ & $105(19.2)$ \\
I have other responsibilities & $144(26.4)$ & $117(21.4)$ \\
My parents would not let me & $26(4.8)$ & $31(5.7)$ \\
I don't know the reason & $84(15.4)$ & $91(16.7)$ \\
Other & $71(13.0)$ & $61(11.2)$ \\
\hline
\end{tabular}

*Note: Percentages represent averages for all sports that students participated in. 


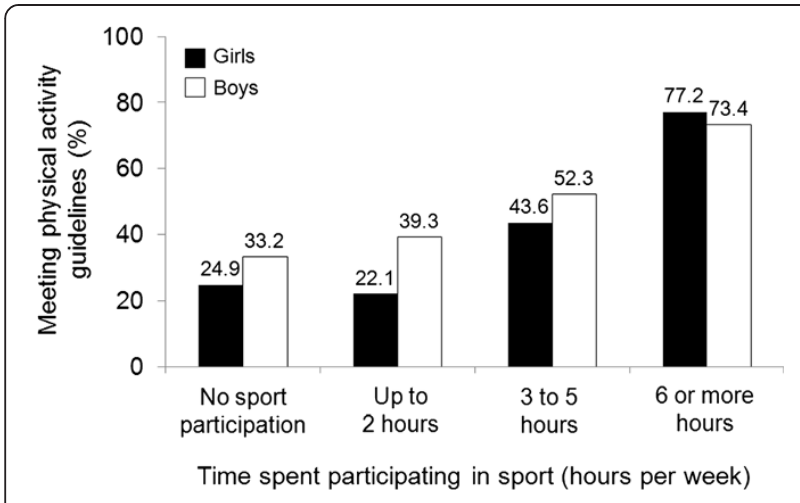

Figure 1 Percentage of boys and girls meeting physical activity guidelines among non-participants and across different categories of time spent in sport for sport participants.

and educational status of the school. In a multivariate model, significant correlates were student's socioeconomic status, PA, screen time, and educational status of the school (Table 3). Compared to students in the highest socioeconomic category, each lower category of

Table 3 Multivariate correlates of sport participation

\begin{tabular}{|c|c|c|c|c|}
\hline & OR & $95 \% \mathrm{Cl}$ & SE & p-value \\
\hline & $\overline{n=1837}$ & & & \\
\hline Age & 0.93 & $0.84-1.03$ & 0.05 & 0.176 \\
\hline Gender & 1.18 & $0.86-1.63$ & 0.18 & 0.289 \\
\hline \multicolumn{5}{|l|}{ NZ Deprivation score } \\
\hline Low & 1.00 & & & \\
\hline Middle-low & 0.75 & $0.49-1.14$ & 0.15 & 0.166 \\
\hline Middle-high & 0.57 & $0.38-0.86$ & 0.11 & 0.010 \\
\hline High & 0.48 & $0.28-0.81$ & 0.12 & 0.008 \\
\hline \multicolumn{5}{|l|}{ Physical activity quintiles } \\
\hline$<60 \mathrm{~min} /$ day & 1.00 & & & \\
\hline 60-89 min/day & 2.89 & $2.10-3.96$ & 0.44 & $<0.001$ \\
\hline 90-119 min/day & 2.81 & $1.68-4.70$ & 0.69 & 0.001 \\
\hline 120-179 min/day & 3.54 & $2.24-5.57$ & 0.77 & $<0.001$ \\
\hline$\geq 180 \mathrm{~min} /$ day & 3.97 & $1.99-7.95$ & 1.31 & 0.001 \\
\hline \multicolumn{5}{|l|}{ Screen time quintiles } \\
\hline$\leq 2$ hours/day & 1.00 & & & \\
\hline 2.1-2.9 hours/day & 1.58 & $0.94-2.65$ & 0.39 & 0.081 \\
\hline 3.0-3.9 hours/day & 1.99 & $1.42-2.80$ & 0.32 & $<0.001$ \\
\hline 4.0-4.9 hours/day & 2.17 & $1.43-3.30$ & 0.43 & 0.001 \\
\hline$\geq 5.0$ hours/day & 1.88 & $1.37-2.57$ & 0.28 & 0.001 \\
\hline \multicolumn{5}{|l|}{ Co-ed school status } \\
\hline Co-ed & 1.00 & & & \\
\hline Boys only & 2.21 & $1.57-3.10$ & 0.36 & $<0.001$ \\
\hline Girls only & 1.12 & $0.79-1.59$ & 0.19 & 0.518 \\
\hline
\end{tabular}

*Table with univariate results is available from the first author. socioeconomic status was associated with lower odds of sport participation $(\mathrm{p}<0.05)$. The reverse trend was observed for PA. Compared to the lowest PA quintile, each higher quintile was associated with increased odds of sport participation $(\mathrm{p}<0.001)$. Higher quintiles of screen time were associated with sport participation $(\mathrm{p}<0.01)$. Finally, students in boys only schools were more likely to participate in sports compared to students from co-educational schools $(\mathrm{p}<0.001)$.

\section{Correlates of time spent participating in sport}

In univariate ordinal regressions, significant correlates of time spent participating in sport were gender, age, student's socioeconomic status, weight status, PA, screen time, availability of sports outside school, quality of sport management, sufficient sport grounds at school, sport results acknowledgment at school, and educational status of the school. Significant multivariate correlates were gender, student's socioeconomic status, weight status, PA, screen time, availability of sports outside of school, quality of sport management, and provision of sport grounds at school (Table 4). Among sport participants, girls spent less time participating in sports compared to boys $(p<0.001)$. In terms of socioeconomic status, students in the middle-high $(\mathrm{p}<0.01)$ and lowest categories $(\mathrm{p}<0.01)$ reported less amount of time spent participating in sports compared to the highest category. Obese students reported less time spent in sports compared to their normal/underweight counterparts $(\mathrm{p}<0.001)$. Time spent participating in sport showed a trend to increase with each higher quintile of PA $(p<0.001)$ and was highest for the highest quintile of screen time $(\mathrm{p}<0.001)$. Availability of sports outside school was associated with more time participating in sports $(p=0.001)$. Similarly, good management of sports $(p<0.001)$ and provision of sufficient sport grounds at school $(\mathrm{p}=0.001)$ increased the odds of students spending more time participating in sports.

\section{Barriers and suggestions for improvement}

The main barriers to sport participation both at school and outside school were lack of interest in sports followed by low perceived competence, lack of time and other responsibilities (Table 2). Lack of available sports and self-presentational concerns were greater barriers for sport participation at school compared to outside school. Among 546 students who did not participate in organised sport, the most common suggestions for improvement in school sports included offering a wider range of sports (15.0\%), making sport more fun and less competitive $(8.8 \%)$, encouraging students to play sports (5.3\%), organizing sports during school time (5.3\%), involving friends, family and teachers (4.9\%), giving awards or paying students $(4.2 \%)$, making sports affordable or 
Table 4 Multivariate correlates of time spent participating in sport

\begin{tabular}{lcccrr}
\hline & \multicolumn{2}{c}{ OR } & $\mathbf{9 5} \%$ Cl & SE & p-value \\
\cline { 2 - 4 } & $\mathbf{n = 1 8 3 7}$ & & & \\
\hline Age & 0.95 & $0.85-1.05$ & 0.05 & 0.282 \\
Gender & 0.56 & $0.43-0.74$ & 0.08 & $<0.001$
\end{tabular}

NZ Deprivation score

$\begin{array}{lllll}\text { Low } & 1.00 & & & \\ \text { Middle-low } & 0.74 & 0.59-0.93 & 0.09 & 0.009 \\ \text { Middle-high } & 0.78 & 0.58-1.04 & 0.12 & 0.093 \\ \text { High } & 0.62 & 0.39-1.00 & 0.15 & 0.048\end{array}$

Weight status

Under/normal weight $\quad 1.00$

Overweight

Obese

Physical activity quintiles

$<60 \mathrm{~min} /$ day

60-89 min/day

90-119 $\mathrm{min} /$ day

120-179 min/day

$\geq 180 \mathrm{~min} /$ day

$0.70-1.42 \quad 0.18$

0.999

$0.31-0.80 \quad 0.12 \quad 0.004$

Screen time quintiles

$\leq 2$ hours/day

$2.1-2.9$ hours/day

3.0-3.9 hours/day

4.0-4.9 hours/day

$\geq 5.0$ hours/day

Availability of sport outside school

Quality of sport management

Sufficient sport grounds and

courts at school

*Table with univariate results is available from the first author.

free $(4.2 \%)$, promoting available sports $(2.9 \%)$, and providing transportation or easier access to sports (2.6\%). Other suggestions, mentioned less frequently, included offering sports lessons, allowing students to choose which games to play, providing more equipment and better coaches, changing the sport schedule, reducing bullying on sports teams, having less homework, offering traveling opportunities, supplying better uniforms, and playing music in the gym.

\section{Discussion}

The results of the present study support the use of sport participation as an effective strategy to increase PA levels. Youth engages in PA through sports, active transport, physical education classes and unstructured PA. Sport participation is a significant component of daily energy expenditure in youth. [7] Similar to findings from United States [23], Canada [24] and New Zealand [5], $70 \%$ of secondary school students in Otago participate in sports. Even though sport participation may not protect against a decline in PA levels during adolescence [25], it is one of the best predictors of PA in early adulthood [8].

Adolescents are more likely to engage in PA when schools provided adequate space, sport grounds and adult supervision. [13] Secondary schools in the Otago region provide excellent support for sports. Availability of sports, adequate coaching and competitions, school support and multiple opportunities for participation most likely contribute to high sport participation rates in this study. Quality of sport management, availability of sports outside school and provision of sport grounds at school were the only modifiable dimensions which predicted more time spent participating in sport. Previous research shows that fun, success, variety, freedom, family participation, peer support and enthusiastic leadership are important for encouraging youth participation in organized sport. [3] Based on suggestions of students not participating in sport in the present study, other areas for school-based interventions include offering a wider range of sports at school, making sport more fun and less competitive, involving friends, family and teachers, and encouraging students to participate. Therefore, programs, interventions and policies designed for promoting PA through sport participation should focus on providing a well-organized sport environment with a wide range of competitive and non-competitive options, making sports available both at school and outside school, providing adequate space and facilities, and offering opportunities for the involvement of friends and family members. This way, promotional efforts can help address perceived barriers to participation identified in this study such as lack of interest and time, and low perceived competence for sports. These efforts should focus preferentially on obese adolescents, students attending co-educational and girls only schools, and, particularly, students living in more deprived neighbourhoods.

Previous studies have found that boys report spending more time in sport participation than girls[23,26]. In the present study, gender differences in sport participation rates were small ( $72 \%$ versus $68 \%$ ) and of borderline statistical significance. However, boys spent more time participating in sports and significantly more boys were meeting minimal physical guidelines solely through sport participation (39\% versus 27\%). Several studies reported a greater total daily energy expenditure in youth sports [7] and higher levels of activity during a sport practice [9] in boys versus girls. These findings are consistent with higher PA levels reported by boys in the present study. In addition, educational status of the school was 
one of the significant multivariate correlates of sport participation in our study. Students in boys only schools were 2 times more likely to participate in sports compared to students from co-educational schools, suggesting the influence of the school culture regarding gender appropriateness of sport participation. One possible explanation for this finding is that boys only schools may be more likely to endorse and promote sport participation than co-educational and girls-only school as a result of gender stereotypes (e.g., prevailing media images) suggesting that sport participation is more appropriate and beneficial for males. Sport participation in girls-only and co-education schools could be promoted by fostering family, peer and teacher involvement and support, in particular those of females, who may act as role models; offering a variety of fun and non-competitive activities, and providing a wider range of sports, some of which may appeal more to girls. Participation could also be promoted by discussing with the students prevailing gender stereotypes about sport participation.

An alarming finding in our study was that lower socioeconomic status, as measured by neighbourhood deprivation score, emerged as a consistent and strong correlate of both participation in sport and time spent in sport. In fact, each lower category of socioeconomic status was associated with lower odds of sport participation. This confirms in a sample from New Zealand that inequities in availability of organized sport programs may also exist in schools and communities based on socioeconomic gradients, corroborating previous findings from Canada and Australia. $[11,27,28]$ In addition, the gradient we observed may reflect lower propensity of lower socioeconomic status individuals to sign up for and persist in a variety of health promotion programs. [29] Improving availability and affordability of developmentally appropriate sport programs for students with lower socioeconomic status, offering a variety of programming choices, providing adequate school grounds for participation, making sure support and encouragement are offered on an ongoing basis, and ensuring opportunities for participants to interact with positive role models, may help these students overcome some of the barriers they face.

Obese adolescents in this study spent fewer hours participating in sport than their normal weight/underweight peers, which is consistent overall with research from Australia [28] and Canada [11]. These adolescents may struggle with issues of body image, and in some cases their skill and fitness levels may not be on par with those of their peers. Consequently, the motivation of those considering participation in sport may be affected negatively. This finding also indicates that obese adolescents already participating in sport may not enjoy their experience as much and be less inclined to persist. Careful planning of the sport environment offered to obese adolescents remains crucial. For example, practices and competitions can be structured in a manner that leads obese adolescents to progressively develop their skills and improve their fitness levels. Likewise, creating an inclusive environment where learning, improvement, effort, and enjoyment are prioritized and reinforced as main goals for participation may contribute to a positive and rewarding experience in sport for obese adolescents as well.

Finally, the findings may seem counterintuitive that both higher rates of sport participation and more time spent participating in sport were associated only with the highest quintile of screen time in our sample; these findings parallel research that indicates the relationship between screen time and physical activity participation is complex. [30] For example, students who participate often in sports may also spend considerable amounts of time in front of the television watching their favorite sports. These students may benefit from being reminded of the negative health consequences of too much time spent sitting in front of the screen, regardless of how physically active they are.

In this study, only one third of students reported meeting minimal PA guidelines solely through participation in organized sports. Taking into account that many sports and related practice drills do not require or provide sufficient PA and energy expenditure to achieve measurable health and fitness advantages (especially for novices) and often involve too much standing or walking around [9,31], this percentage of students meeting PA through sport participation is likely to be overestimated. Studies of youth sport practices found that approximately half of the practice time (43\% to $54 \%$ ) is spent in sedentary or light-intensity activities. [6,9] The situation may be further exacerbated by limited resources and space for sport practices, inappropriate coach-to-child ratios, and personal priorities of coaches and administrators resulting in less than adequate amount and intensity of PA associated with sport participation.[31]

Sport participants reported a greater weekly amount of moderate-to-vigorous PA compared to their peers. [32] In our study, both sport participation and the time spent in sports were associated with higher levels of PA. The percentage of students meeting PA guidelines increased significantly from $29 \%$ of students who participate in sports up to 2 hours per week to $75 \%$ of students who participate for 6 or more hours per week. Therefore, although sport participation represents an important opportunity for increasing PA in youth, this alone may not be sufficient for meeting PA recommendations in most adolescents. To increase overall exercise intensity and energy expenditure and maximize activity and playing 
time, sports program organizers need to plan to establish teams and groups with small number of students per coach, court and field. [31] Coaches should ensure that activities during sport practices are structured to maximize PA intensity and involvement for all participants. In addition to organized sports, adolescents need to be encouraged to adopt an active lifestyle, incorporate PA in their everyday life such as active transport, and engage in physical activities outside of organized sport.

Study limitations include lack of random sampling of students, which was not feasible in the present study. However, we recruited 19 out of 23 schools in the Otago region of New Zealand. The non-participating schools were high decile and therefore students with lower socioeconomic status were not undersampled in the present study. In addition, findings are based on selfreported data, which may have introduced response biases such as acquiescence and social desirability biases. The careful design of the survey questions, along with pre-testing and pilot testing, as explained in the Methods section, also contributed to prevent or minimize biases. The cross-sectional design precludes comparing data across different seasons and the possibility of making causal inferences. Future studies should consider incorporating longitudinal designs.

In summary, both sport participation and the time spent participating in sports are associated with higher levels of PA in adolescents. Interventions, programs and policies should address the needs of adolescents living in more deprived neighbourhoods and those who are obese, while being sensitive to the culture of the school regarding stererotypes about what is gender appropriate. Possibilities for intervention include increasing availability of sports, improving the quality of sport management, providing sport grounds at school, offering a wide range of enjoyable competitive and non-competitive options, and fostering interaction with family, peers, and teachers. Encouraging adolescents to participate in sports and providing them with opportunities to do so is an effective strategy to increase overall PA in youth. Adolescents who do not enjoy participating in organized sports should be encouraged to engage in other forms of PA such as unstructured activities, active transport and physical education classes.

\section{Abbreviations \\ METs: Metabolic equivalents; PA: Physical activity.}

\section{Competing interests}

The authors declare that they have no competing interests.

\section{Authors' contributions}

SM and PS were the principal investigators for this overall project, contributed to the conception and design of the project and monitored questionnaire design and data collection process. SM also contributed to data analysis and interpretation for this study, drafted and revised the manuscript. PS also revised the draft manuscript. EBG contributed to conceptualization of this particular study, data analysis and interpretation and manuscript writing and revisions. ES assisted with data collection, management and analysis and manuscript revisions. SLB assisted with data analysis and interpretation and revised the draft manuscript. All authors read and approved the final manuscript.

\section{Acknowledgements}

The study was a collaboration between the University of Otago, Dunedin City Council, Otago Regional Council and Otago Secondary School Sports Association. We would like to acknowledge all collaborators who assisted with this project (Charlotte Flaherty, Hamish Black, Michael Laufiso, Jane Turnbull, Peter Taylor and Des Smith) and research assistants and support personnel who assisted with data collection (Kylie Jessop, Sarah Featherston, Victoria Logan, Hamish Gould). Finally, we would like to thank all Secondary Schools in the Otago region for taking part in the project, providing computer facilities and access to students during their class time, and assisting with supervision of students during data collection.

The project was funded by Dunedin City Council and Otago Regional Council and was supported by the University of Otago.

\section{Author details}

${ }^{1}$ School of Physical Education, University of Otago, PO Box 56, Dunedin, New Zealand. ${ }^{2}$ Department of Kinesiology and Physical Education, McGill

University, Montreal, Canada. ${ }^{3}$ Department of Preventive and Social Medicine, University of Otago, Dunedin, New Zealand. ${ }^{4}$ Department of Human Nutrition, University of Otago, Dunedin, New Zealand.

Received: 9 January 2012 Accepted: 26 June 2012

Published: 12 July 2012

\section{References}

1. World Health Organization: Inequalities in young people's health. Health Behaviour in School Age Children International Report from the 2005/2006 survey. Copenhagen: World Health Organization Europe; 2008.

2. Guthold R, Cowan MJ, Autenrieth CS, et al: Physical activity and sedentary behavior among schoolchildren: a 34-country comparison. J Pediatr 2010, 157(1):43-49. e41.

3. Washington RL, Bernhardt DT, Gomez J, et al: Organized sports for children and preadolescents. Pediatrics 2001, 107(6):1459-1462.

4. Marsh HW, Kleitman S: School athletic participation: Mostly gain with little pain. J Sp Sci Ex Psych 2003, 25:23.

5. Adolescent Health Research Group: Youth '07: The Health and Wellbeing of Secondary School Students in New Zealand. Initial findings. Auckland: The University of Auckland; 2008.

6. Wickel EE, Eisenmann JC: Contribution of youth sport to total daily physical activity among 6- to 12-yr-old boys. Med Sci Sports Exerc 2007, 39(9):1493-1500

7. Katzmarzyk PT, Malina RM: Contribution of organized sports participation to estimated daily energy expenditure in youth. Pediatr Exerc Sci 1998, 10(4):8.

8. Telama R, Yang $X$, Viikari J, et al: Physical activity from childhood to adulthood: a 21-year tracking study. Am J Prev Med 2005, 28(3):267-273.

9. Leek D, Carlson JA, Cain KL, et al: Physical activity during youth sports practices. Arch Pediatr Adolesc Med 2011, 165(4):294-299.

10. Santos M, Esculcas C, Mota J: The relationship between socioeconomic status and adolescents' organized and nonorganized physical activities. Pediatr Exerc Sci 2004, 16:210-218.

11. Garcia Bengoechea E, Sabiston CM, Ahmed R, et al: Exploring links to unorganized and organized physical activity during adolescence: the role of gender, socioeconomic status, weight status, and enjoyment of physical education. Res Q Exerc Sport 2010, 81(1):7-16.

12. Barr-Anderson DJ, Young DR, Sallis JF, et al: Structured physical activity and psychosocial correlates in middle-school girls. Prev Med 2007, 44(5):404-409.

13. Sallis JF, Conway TL, Prochaska JJ, et al: The association of school environments with youth physical activity. Am J Public Health 2001, 91(4):618-620.

14. McKenzie TL: Health-related physical education: physical activity, fitness, and wellness. In Student learning in physical education: applying research to enhance instruction. 2nd edition. Edited by Silverman SJ, Ennis CD. Champaign, LL: Human Kinetics; 2003:207-226. 
15. Salmond C, Crampton P, King P, et al: NZiDep: a New Zealand index of socioeconomic deprivation for individuals. Soc Sci Med 2006, 62(6):1474-1485.

16. Cole TJ, Bellizzi MC, Flegal KM, et al: Establishing a standard definition for child overweight and obesity worldwide: international survey. BMJ 2000, 320(7244):1240-1243.

17. Corder K, van Sluijs EM, Wright A, et al: Is it possible to assess free-living physical activity and energy expenditure in young people by self-report? Am J Clin Nutr 2009, 89(3):862-870.

18. Ridley $\mathrm{K}$, Ainsworth BE, Olds TS: Development of a compendium of energy expenditures for youth. Int J Behav Nutr Phys Act 2008, 5:45.

19. Troiano RP, Berrigan D, Dodd KW, et al: Physical activity in the United States measured by accelerometer. Med Sci Sports Exerc 2008, 40(1):181-188.

20. Maddison R, Turley M, Legge $N$, et al: A National Survey of Children and Young People's Physical Activity and Dietary Behaviours in New Zealand: 2008/ 09. Technical Report. Auckland: The University of Auckland: 2010.

21. Riddoch CJ, Bo Andersen L, Wedderkopp N, et al: Physical activity levels and patterns of 9- and 15-yr-old European children. Med Sci Sports Exerc 2004, 36(1):86-92.

22. World Health Organization: Global recommendations on physical activity for health. Geneva, Switzerland:; 2010.

23. Pate RR, Trost SG, Levin S, et al: Sports participation and health-related behaviors among US youth. Arch Pediatr Adolesc Med 2000, 154(9):904-911.

24. Active Healthy Kids Canada: Healthy Habits Start Earlier than You Think. The Active Healthy Kids Canada Report Card on Physical Activity for Children and Youth. Toronto, ON:: 2010.

25. Belanger M, Gray-Donald K, O'Loughlin J, et al: Participation in organised sports does not slow declines in physical activity during adolescence. Int J Behav Nutr Phys Act 2009, 6:22.

26. Johnston LD, Delva J, O'Malley PM: Sports participation and physical education in American secondary schools: current levels and racial/ ethnic and socioeconomic disparities. Am J Prev Med 2007, 33(4 Suppl):S195-208.

27. O'Loughlin J, Paradis G, Kishchuk N, et al: Prevalence and correlates of physical activity behaviors among elementary schoolchildren in multiethnic, low income, inner-city neighborhoods in Montreal, Canada. Ann Epidemiol 1999, 9(7):397-407.

28. Salmon J, Timperio A, Cleland V, et al: Trends in children's physical activity and weight status in high and low socio-economic status areas of Melbourne, Victoria, 1985-2001. Aust N Z J Public Health 2005, 29(4):337-342

29. Gauvin L: Social disparities and involvement in physical activity: Shaping the policy agenda in healthy living to successfully influence population health. 2003 [cited January 15, 2008]; http://www.gris.umontreal.ca/ rapportpdf/R03-02.pdf.

30. Biddle SJ: Sedentary behavior. Am J Prev Med 2007, 33(6):502-504.

31. Bergeron MF: Improving health through youth sports: is participation enough? New Dir Youth Dev 2007, 115:27-41. Fall 26

32. Sallis JF, Prochaska JJ, Taylor WC: A review of correlates of physical activity of children and adolescents. Med Sci Sports Exerc 2000, 32(5):963-975.

\section{doi:10.1186/1479-5868-9-86}

Cite this article as: Mandic et al:: Getting kids active by participating in sport and doing It more often: focusing on what matters. International Journal of Behavioral Nutrition and Physical Activity 2012 9:86.

\section{Submit your next manuscript to BioMed Central and take full advantage of:}

- Convenient online submission

- Thorough peer review

- No space constraints or color figure charges

- Immediate publication on acceptance

- Inclusion in PubMed, CAS, Scopus and Google Scholar

- Research which is freely available for redistribution 